\title{
THORACOSCOPY AS AN AID TO DIAGNOSIS IN CONGENITAL HEART DISEASE
}

\author{
BY \\ L. FATTI AND J. C. GILROY \\ From Baragwanath Hospital, Johannesburg Hospital Board, South Africa \\ Received May 12, 1949
}

The advent of surgery in the treatment of congenital heart disease has meant that accuracy in the detailed diagnosis of the anatomy of the great vessels has become a matter of paramount importance instead of, as was formerly the case, an interesting mental exercise. Especially is this so when we are dealing with cyanotic heart disease, of which Fallot's tetralogy forms 70 per cent of cases. Anomalies additional to the classical four are not uncommon and may compel an exploratory thoracotomy before a decision can te made as to which side is the better surgical approach.

Blalock (1946, 1947, and 1948) advocates that the approach be made on the side of the innominate artery, and points out that if the aortic arch is right-sided, the innominate artery is located on the left side. There is, however, as he states, a wide variation in the arteries arising from the aorta, and in some cases all four arteries have arisen independently from the aortic arch, there being no innominate artery at all. In 1947 he suggested the more extensive use of visualisation of the heart and great vessels by the injection of radio-opaque substances, but even this method leaves unsolved many questions that can only be answered after the vessels have been examined by direct vision.

These difficulties were brought home to us in the recent case of a boy of 14 on whom we operated, with Fallot's tetralogy and a complete right-sided aorta. Following Blalock's suggestion that in such cases the innominate subclavian was more likely to be found in the left hemithorax, a left thoracotomy was performed. The aortic arch was found to be high in the mediastinum, with the subclavian coming directly from its upper medial aspect. There was a gap of about an inch between the aortic arch and the hypoplastic pulmonary artery, but it proved impossible to bridge this by the short avail- able subclavian artery even though a maximal length had been freed and turned down.

After this disappointment it was decided to attempt another diagnostic investigation in future cases, namely thoracoscopy after the induction of pneumothorax. Apart from the advantage that it is not such a major procedure as thoracotomy one hoped that this would supply the answer to many questions that exercise the mind of the surgeon before operating, such as the calibre and condition of the vessel wall, the extent of coarctation, and the condition of the aorta beyond the constriction. Thoracoscopy can be done on the table as a preliminary to immediate operation, or it can be done some days previously.

The following cases illustrate the use of this technique, the limitations and possibilities of which are still being investigated.

Case 1. A puny but intelligent girl, aged 7, was deeply cyanosed with gross parrot-beaked clubbing of fingers and toes. Clinically she appeared to be a case of dextrocardia with Fallot's tetralogy. On X-ray examination there was a pulsating shadow projecting from the heart on its left side and behind it. This shadow was provisionally interpreted as an enlarged auricle, possibly due to patent interauricular septum. Angiocardiography indicated that the ascending and transverse portions of the aortic arch and about one inch of the descending aorta were on the right side. Barium swallow showed no notching of the œesophagus to suggest a vessel crossing behind (Williams, 1947).

A left-sided pneumothorax was induced with $300 \mathrm{ml}$. of air. The next day a thoracoscope (G.U. type $9 \mathrm{~mm}$. diameter) was inserted in the 6th left interspace near the angle of the rib, the patient lying on her right side. The lung was lying on the mediastinum but could be pushed out of the way 
with the thoracoscope to reveal a "pulsating tumour" behind; the tumour was pink, smooth, retropleural and its pulsations were expansile; it emerged from the mediastinum and descended alongside the spine to disappear behind the lung. It was in fact the aorta which had crossed over the spine from the right side. The subclavian artery was concealed by the lung as it lay on the mediastinum.

Case 2. A Msutu boy, aged 3, suffered from coarctation of the aorta. He had had four episodes of left ventricular failure with triple rhythm, an alternating pulse $(10 \mathrm{~mm}$. of mercury) and moist sounds in the lungs, but when admitted his general condition was fairly good and failure had cleared apart from some rales in the left lung. Both carotids were pulsating vigorously, and the apex beat was in the sixth left interspace in the anterior axillary line. The femoral pulses could not be felt. A systolic murmur was heard over the third left interspace just lateral to the sternum. The blood pressure was $110 / 90$ in the left arm and 170/120 in the right. There was some retarded development of the buttocks and legs.

$\mathrm{X}$-ray examination confirmed the enlargement of the left ventricle and showed a normal aortic knuckle, but also slight enlargement of the right ventricle. There was notching of the ribs on the right side though not on the left. The following suggestions were made to account for his right ventricular enlargement.

(a) A patent interventricular septum, but the murmur was atypical.

(b) A co-existing patent ductus arteriosus without the characteristic machinery murmur. In view of the child's age it was difficult to dismiss this possibility, which would imply that the coarctation was infantile in type with a wider area of stenosis than usual. This was supported by the absence of notching of the left ribs.

(c) The four previous attacks of left-sided heart failure had resulted in hypertrophy of the right ventricle. The pulmonary vascular X-ray shadows were noted to be heavy.

Induction of a pneumothorax followed by screening and, if necessary, thoracoscopy presented itself as the simplest means of deciding, and was performed on the left side with $500 \mathrm{ml}$. of air. Screening showed that the lung was partially collapsed and, with the child vertical, was falling away from the mediastinum. The aortic knuckle pulsated vigorously, but seemed to be cut short about the middle of the arch. Three days later a thoracoscope was inserted in the 4th left interspace between the scapular border and the spine, the patient lying on his right side. Because the lung overlay the mediastinum the patient was then turned on his left side, and the table tilted into a moderate counter-Trendelenburg position. The view now obtained through a right angle vision telescope had completely changed: the lung had fallen outwards, downwards and forwards, putting the pulmonary hilus on a slight stretch (Fig. 1). The aortic arch was well exposed as it emerged from under the thymus, and the descending aorta could be viewed from above for a considerable part of its length towards the diaphragm. A tight coarctation was identified involving the root of a very small subclavian artery and extending for about $1 \mathrm{~cm}$. outwards. The descending aorta was pulsating less than the arch above the coarctation, and there was less discrepancy between the calibre of the aorta distal and proximal to the coarctation than had been expected. Several large upper intercostal vessels were seen, and also a large internal mammary artery. The vasa vasorum on the descending arch just distal to the constriction were dilated. A good view of the surface of the lung hilus was obtained. No ductus arteriosus was visible nor fold of pleura raised by a ligamentum arteriosum. The lung and descending aorta appeared normal. After withdrawing the telescope air was sucked out of the chest and the wound closed with a stitch. The child slept for six hours following this procedure but next day developed a consolidation of the middle lobe of the right lung, from which he made an uneventful recovery. However, at operation one month later he died after the chest was opened and before the coarctation was excised. The heart stopped beating and could not be made to contract again. Postmortem the heart weighed 121 grams, showing marked hypertrophy of the left ventricle and, to a less degree, of the right ventricle. There was no patent ductus arteriosus. The coarctation was confirmed at the level of the root of the atresic subclavian artery. Microscopic examination showed extensive perivascular fibrosis of the myocardium and intimal plaques of calcium in the coronary arteries.

Case 3. A European boy, aged 7, suffered from Fallot's tetralogy. He had been blue since the age of one year and cyanosis was increased by exertion. He could not run at all fast, and after ambling for about 30 yards he would squat on his heels.

On examination the veins of the neck were engorged above the angle of Lewis. The fingers were clubbed and the nails were cyanosed as was the face, even when at rest in bed. Arterial pulsation was visible above the clavicles. The apex beat was within normal limits, but there was a heaving impulse over the præcordium. A systolic murmur was present over the whole præcordium, loudest over 
the second left intercostal space. There was no enlargement of liver or spleen. Blood pressure $110 / 90$ in both arms. The red cell count was $7,100,000$. X-ray examination showed right ventricular enlargement with the aortic knuckle on the left. The pulmonary conus was visible but diminished on its under side. The pulmonary vascular shadows were slight, especially towards the lung periphery. There was right axis deviation.

A right pneumothorax was induced with $400 \mathrm{ml}$. of air and a thoracoscope (Coryllos-direct) was inserted into the first right intercostal space in the midclavicular line. The subclavian artery was well difficulty in performing the anastomosis and this was confirmed by immediate thoracotomy on the right side.

Case 4. A Zulu girl, aged 9, was admitted in congestive heart failure. No good history could be obtained and it was impossible to find out whether she had ever suffered from rheumatism or not. The veins of the neck were engorged and pulsating two inches above the angle of Lewis. She had œdema of both ankles and an enlarged liver, but was not unduly breathless when lying in bed, but stated she was breathless when on her feet. Blood

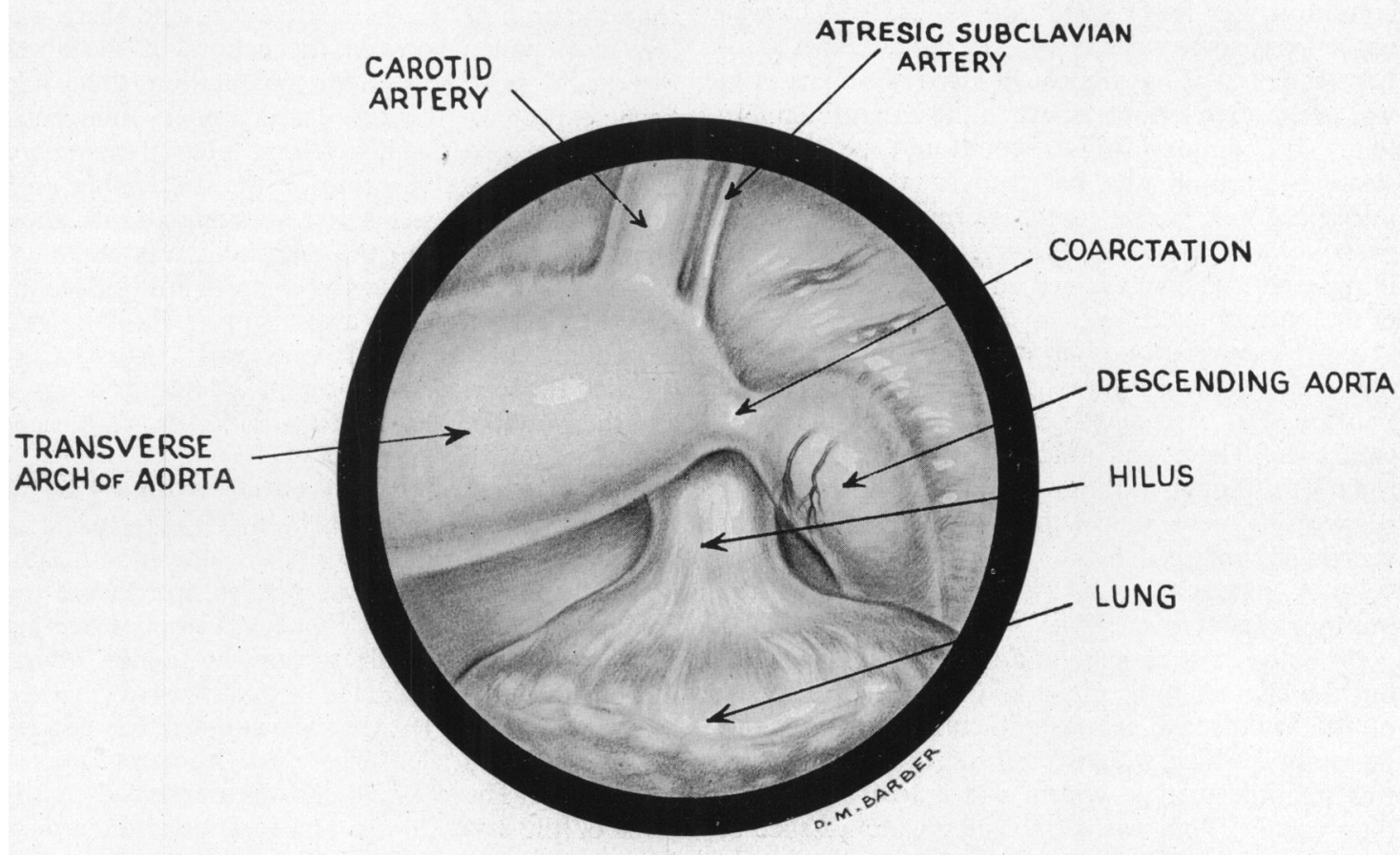

Fig. 1.-Case 2. Aortic arch seen from the side and above by right-angled telescope.

visualized and also a considerable number of collateral vessels. The subclavian appeared to be a large artery and raised a ridge on the mediastinal pleura. A large innominate vein was seen with a vein running from it to communicate with a large azygos. The pulmonary artery could not be identified because of numbers of small engorged veins just above the hilus of the lung and the azygos vein. Although the pulmonary vessels could not be seen their position was estimated approximately from the level of the hilar pleura. The aortic arch was viewed travelling towards the left and not descending on the right side. The appearance of the subclavian artery suggested that there would be no pressure 104/60. Pulse regular 144. The apex beat was in the 5th space just outside the midclavicular line. The præcordium was bulging and a diffuse heaving impulse was visible, with an apical systolic thrill. There was a harsh systolic murmur loudest over the apex but audible over the whole præcordium. In the 2nd left interspace an inch outside the sternal margin, there was also a sound that at times seemed to fill the whole diastolic pause, but because of the tachycardia it was difficult to decide whether this was really a machinery murmur or a third closed sound. Phonocardiography did not help. After a week's treatment with digitalis she came out of failure but her pulse rate never came 
down below 120. X-ray examination and screening revealed a mitral-shaped heart, considerably increased in its transverse diameter. Both ventricles were enlarged, the right more than the left, and also the left auricle. The aorta appeared to be hypoplastic. There was some vascular congestion of both lung fields but no hilar dance. Various diagnoses were considered.

Cardiac catheterization (Dr. van Lingen) gave no evidence of an intracardiac vascular shunt. The catheter point failed to pass into the pulmonary valve and appeared to be washed back from it, which was regarded as evidence of pulmonary incompetence. However, in spite of the atypical $\mathrm{X}$-ray and blood pressure we decided, in view of the child developed acute nephritis and operation has had to be deferred. Her heart rate is slower and the murmur is now typically machinery in character.

Case 5. A European boy, aged 9, was sent in as a case of coarctation of the aorta. The blood pressure in both arms was 150/120 and his femoral pulses could not be felt. His condition was complicated by petit mal. $\mathrm{He}$ was otherwise a bright and normal boy. It was decided to control the petit mal with phenobarbitone before operating and to perform thoracoscopy with the idea of not only viewing the coarctation but of assessing any change in the condition of the aorta that might occur subsequently.

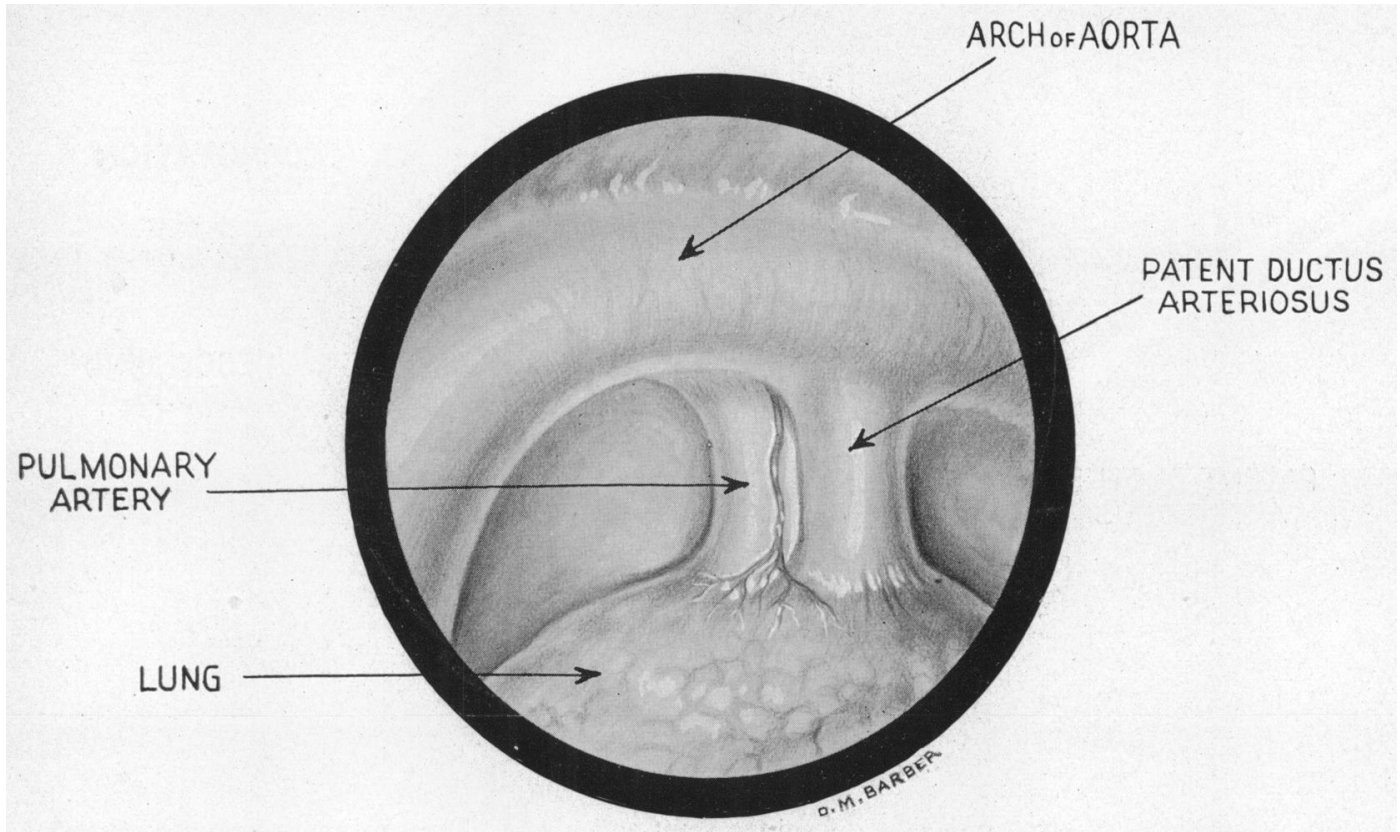

FIG. 2.-Case 4. View of aortic arch and lung root seen from above. Distorsion of the aortic arch is due to the proximal part to the left, being closer to the telescope than the other end.

very suggestive murmur, to attempt to exclude a patent ductus by means of thoracoscopy. Accordingly, a left pneumothorax was induced and a thoracoscope introduced by a posterior approach in the 4th left interspace close to the scapula with the child lying on her left side. This gave a good view of the hilus, and showed a large vessel underneath the aortic arch in close contact with it (Fig. 2). It was, however, difficult at the time to establish whether this was a patent ductus or the pulmonary artery. Its apparent origin from the anterior surface of the aortic arch strongly suggested a ductus, and in the light of further experience we are now convinced that this was so. Meanwhile the $2 \mathrm{E}$
A left pneumothorax was induced with $400 \mathrm{ml}$. of air and the thoracoscope was inserted immediately, using the anterior approach in the $2 \mathrm{nd}$ left interspace in the midclavicular line. An excellent view was obtained with the direct and also with the right-angled telescope. The coarctation was seen to be about a quarter of an inch long and slightly less in its outside diameter. The transverse aortic arch was dilated. Dilated subclavian and internal mammary arteries were clearly visible (Fig. 3). Unexpectedly a patent ductus arteriosus was seen arising close to the beginning of the coarctation, clearly separated from the pulmonary artery by a gap, and having a lymph gland overlying it. A small 
vascular leash crossed over the ductus arteriosus. The vagus nerve, flanked by small arteries, hooked underneath and disappeared behind the hilus. The objective lens of the telescope could be brought into contact with the duct and its impulse with no thrill was easily felt on the shank of the thoracoscope. This manœuvre caused some discomfort to the patient. The ductus was wide and appeared to dilate aneurysmally with each pulsation. This patient is now awaiting operation, which seems imperative owing to risk of rupture of his aorta, enlargement; no thrill. A soft machinery murmur was heard in the 2nd left intercostal space, audible also at the vertebral border of left scapula in 2nd and 3rd interspaces. Blood pressure 150/60. Femoral pulse easily palpable.

A left pneumothorax was induced with $600 \mathrm{ml}$. of air. The thoracoscope was introduced immediately through an anterior approach in the 2 nd left intercostal space in the midclavicular line. A very blue pulsatile pulmonary artery was seen with an almost orange coloured ductus arteriosus rising

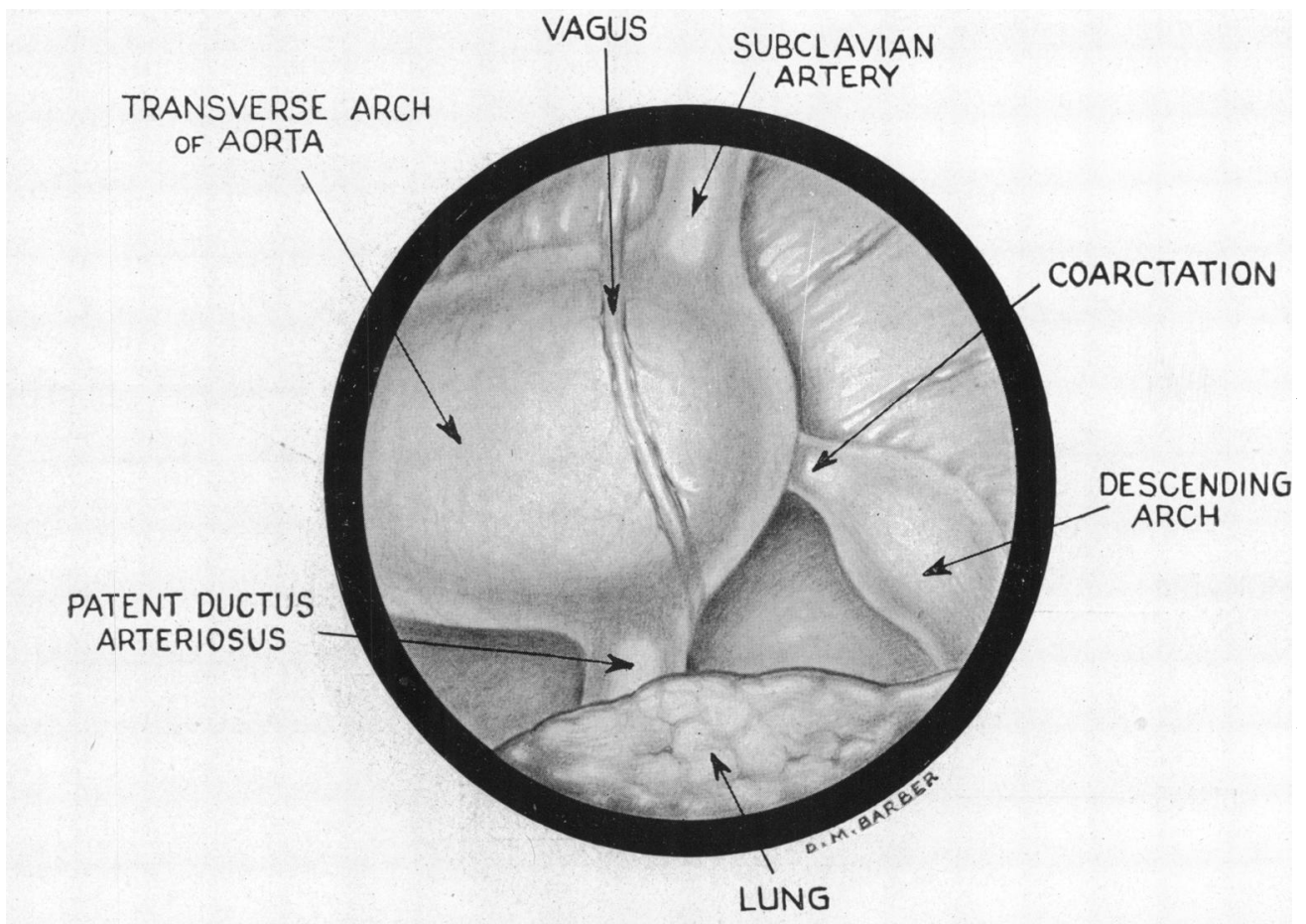

Fig. 3.-Case 5. The aortic arch seen from the front and above. The proximal aorta was greatly dilated and overlay the beginning of the coarctation. The vagus and its accompanying small vessels were more visible than usual.

the proximal part of which is very dilated. The ductus arteriosus will be ligated at the same time. At the moment he is undergoing treatment to control his epilepsy.

Case 6. A woman, aged 21, noticed no symptoms as a child, but a "machinery murmur" was heard at the age of 9 , and for this reason she was refused life assurance a few months ago. For the past three years she has been listless, tired, breathless on exercise, and dizzy on bending. She is due to get married shortly.

On examination, slight pulsation in the neck and second left intercostal space; no clinical cardiac from the antero-inferior aspect of the aortic arch (Fig. 4). Pulsation of the ductus was less than that of the pulmonary artery. A small arterial leash was visible on the surface of the ductus with two small lymphatic glands along side. The aorta appeared to be somewhat angulated just proximal to the ductus but was otherwise normal. Operation performed on the following day confirmed these findings but, in addition, revealed a very slight indentation of the aorta just proximal to the ductus at the site where an infantile coarctation occurs. A very marked systolic thrill was palpable in the ascending arch up to the site of the constriction. By auscultation before and after ligation and 
division of the ductus we both confirmed the disappearance of the murmur after ligation. Two days after operation it had returned, and this was confirmed when seen again one month later.

Case 7. A European male, aged 19, complained of slight blueness and dyspnœa, both aggravated by exercise, occasional slight giddiness on exercise, and some palpitation. His mother noted cyanosis at birth, aggravated by crying. He had been difficult to rear, but had suffered from the usual children's marked in the lips, tip of nose, lobes of ears, fingers, and toes. Eyes suffused and marked clubbing of fingers. No venous engorgement in the neck. Blood pressure, right arm 125/60, left arm 115/60. No abnormality or evidence of congestion found in the lungs. Apex beat forcible and diffuse within the mid-clavicular line and in the 5th and 6th intercostal spaces. At the base of the heart there was a mild thrill with a loud systolic murmur in the second left space: this murmur was localized, but a softer systolic murmur was heard over the rest of

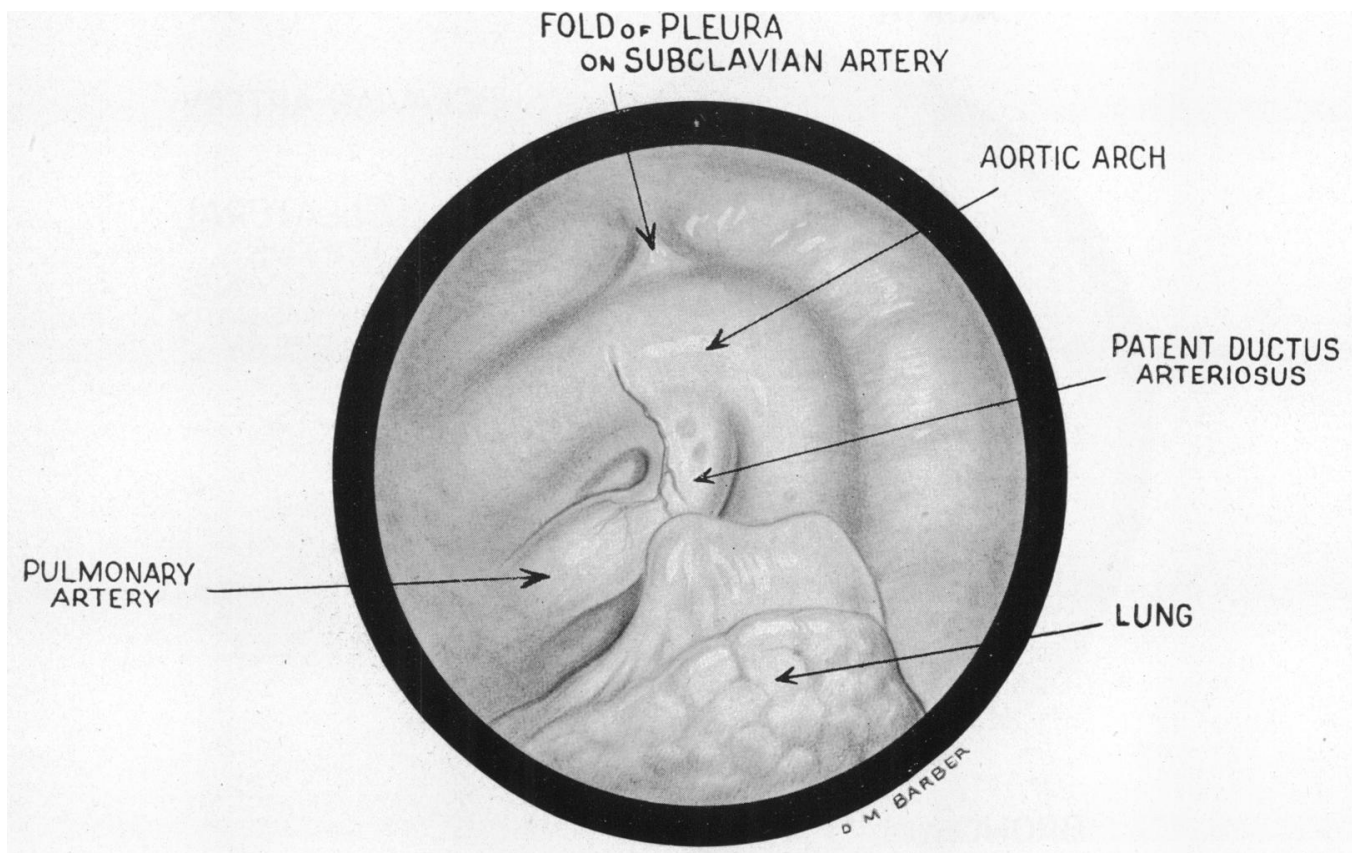

FIG. 4.- Case 6. Aortic arch and lung root seen from the front and above. The arch is more acutely angled than usual.

diseases, including whooping cough, without trouble. Walking was delayed until after the third year. No other members of the family suffered from congenital defects; his mother had been healthy during pregnancy and the labour had been normal.

Although early growth was retarded his height is $5 \mathrm{ft} .11 \mathrm{in}$. and weight $117 \mathrm{lb}$. His present activity is restricted to walking on the flat without hurrying. Cyanosis, which is minimal at rest, becomes pronounced on moderate exercise and during extremes of weather. Squatting is not marked, but he adopts a knee-chest position for comfort when fatigued. The parents think he has improved during recent years and are interested in the possibility of a Blalock-Taussig operation.

On examination, slight generalized cyanosis more $2 \mathrm{E}^{*}$ the præcordium. The second sound was closed and much accentuated in the 2nd left intercostal space. Radioscopy showed some cardiac enlargement predominantly right ventricular, although the left ventricle was also enlarged to a lesser degree. The aorta pulsated vigorously. In the antero-posterior view the pulmonary conus was slightly prominent and not concave, but the left oblique view suggested that the pulmonary artery was small. Despite the prominence of the lung markings no pulsation was seen. A barium swallow showed the aorta to arch downwards on the left side. The X-ray evidence favoured Fallot's tetralogy with a good collateral circulation through a patent ductus or bronchial arteries; it did not suggest Eisenmenger's complex. Venous catheterization of the heart (Dr. van Lingen) 
demonstrated the ventricular septal defect by passing the catheter through it, and analysis of blood samples suggested a right to left shunt. An overriding aorta was demonstrated with reasonable certainty by the fact that the oxygen content of the left ventricular blood was higher than that from femoral artery puncture. Failure to record pressures in the pulmonary artery or to obtain equal systolic pressures in the aorta and right ventricle precluded differentiation between Fallot's tetralogy and an Eisenmenger complex. The final diagnosis colour and slightly tortuous, which entered the hilum as a network and almost hid the pulmonary artery. A few enlarged vessels were to be seen on the lung surface. In the angle between the subclavian artery and the curve of the arch another and thicker plexus of dark vessels was seen, presumably collaterals of the intercostal arteries dipping under the arch to enter the hilum. The vessels on the surface of the aortic arch numbered about 25, extending from the ascending aorta over to the descending, many more than would be expected from

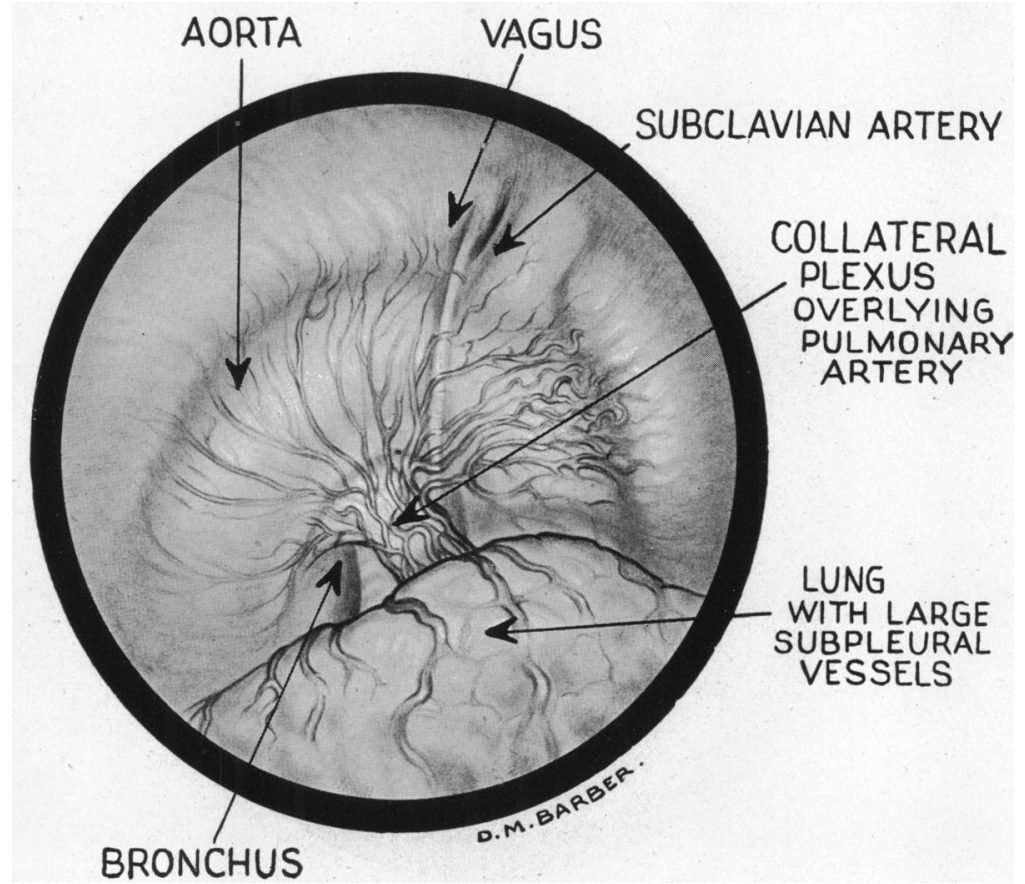

FIG. 5.-Case 7. The aortic arch seen from the front and above. Note the plexus of collateral vessels crossing the aortic arch to reach the hilum and overlying the pulmonary artery. The arrows indicating the vagus and the bronchus are a fraction too far to the left.

was Fallot's tetralogy with a possible patent ductus arteriosus or a collateral circulation to the lungs by bronchial arteries.

It was decided to submit this case to thoracoscopy in order to determine what form of collateral circulation was present and also, if possible, to take the pressure in the pulmonary artery by means of a needle introduced and withdrawn under direct thoracoscopic vision. A pneumothorax was introduced with $400 \mathrm{ml}$. of air, and the thoracoscope inserted in the 2 nd left interspace in the midclavicular line, the patient reclining at an angle of $45^{\circ}$ to the horizontal. The aortic arch was immediately seen, and presented a remarkable picture (Fig. 5) being crossed radially by numerous vessels, dark blue in bronchial arteries alone and some seemed to come from the enlarged internal mammary artery. The pulmonary artery was small, and through another cannula, about an inch lateral to the first, a long needle was inserted into its small exposed part. The systolic pressure, read on a saline-citrate manometer, registered $20 \mathrm{~cm}$. above the manubrium (normal $25 \mathrm{~cm}$.). On removing the needle only a few drops of blood were seen and, when washed off with saline, did not reappear. Air was aspirated from the chest, the cannula removed and the wounds closed with one Michel's clip each. No untoward effects were noted by the patient, nor had any sensations been felt during the needling of the vessel. 
The thoracoscopic finding confirmed that the collateral supply to the lung was good, though not provided by a ductus arteriosus. It also showed that, although the pulmonary artery was small, the extensive collaterals were enough to raise its pressure even at the hilum to four-fifths of the normal, and that it is easier to obtain the pulmonary arterial pressure by this method than by cardiac catheterization in cases of narrowing of the pulmonary infundibulum or valves.

On the reasonable assumption that a similar collateral supply was present on both sides of the aortic arch, it was thought wiser not to perform Blalock's operation on this patient.

\section{ANesthesia AND TeChNiQue}

In adults, local anæsthesia is the anæsthetic of choice, with omnopon, one-third of a grain, given an hour before. With suitable doses of omnopon the same anæsthesia applies to children down to the age of 7 or 8 years. Below this age, various types of general anæsthesia are used with equal success, and we have successfully given intravenous nembutal, or cyclopropane and oxygen after a basic narcotic of seconal, or ether by the closed method after a similar basal narcotic. Insufficient narcosis causes difficulty from restlessness and irregular movements of the chest, as the child is too unconscious to co-operate and not deep enough to be quiet. Even trilene anæsthesia is fairly satisfactory in spite of the rapid breathing if a large enough pneumothorax is induced. In children of five to eight years, 400 to $500 \mathrm{ml}$. of air can be introduced without distress.

The procedure of thoracoscopy need not be enlarged upon, as its technique is well known, but a few special points are worthy of mention. The pneumothorax is induced in the operating theatre, immediately before the operation, unless the lung is expected to be adherent, when the induction is done under an X-ray screen a day or two before. If there is widespread adhesion this method of investigation must of course be abandoned.

After trying various sites of introduction we have found the most satisfactory approach to be the anterior, in the second interspace in the midclavicular line, with the table tilted to an angle of about $45^{\circ}$ in the counter-Trendelenburg position. A lateral tilt may be added, but is only occasionally necessary, if the greater part of the descending thoracic aorta is to be seen. For the visualization of a coarctation or of a patent ductus the direct telescope gives the best view; this should, however, be supplemented by the right-angled view, especially if the thymus or the internal mammary artery are to be seen. The subclavian artery in Fallot's tetralogy is better seen with a right-angled telescope but the direct telescope should also be available in order to obtain as good a three-dimensional idea as possible. When investigating coarctation, it is as well to insert the trocar and cannula as nearly as possible in the centre of the intercostal space to avoid both an enlarged intercostal artery and its anterior branch running along the upper border of the rib below; in practice, we have not met with this complication.

Any thoracoscope with direct and right-angled telescopes can be used; the 9-mm. Gullbring type as modified by the Genito-Urinary Co. has been very satisfactory; the 7-mm. Coryllos type gives a smaller field which is its only disadvantage. Oxygen can be given during the investigation, but is usually unnecessary even with cyanotic children, unless a very large collapse of the lung has been produced. The major operation can be proceeded with immediately, as was done in Case 3; no harm seems to have accrued from this, nor is it to be expected.

\section{Discussion}

We believe that thoracoscopy is a useful diagnostic procedure in certain congenital abnormalities of the great vessels and may give information that cannot be gained by X-ray examination even with the use of radio-opaque substances. The injection of these substances into the basilic vein often gives unsatisfactory results and when they are injected into the right auricle there is an appreciable risk to the patient's life, which is absent when the alternative procedure of thoracoscopy is employed.

As was only to be expected the hilar structures cannot always be visualized distinctly but, on the other hand, the gap to be bridged between the aortic arch and the pulmonary artery can be estimated fairly accurately. This was so in Case 3, where the pulmonary vessel was covered by a thick network of collateral veins and the artery could not be seen, though its position could be assessed with reasonable accuracy. In patent ductus arteriosus our experience indicates that an anterior approach gives a better view of the anatomy than a posterior and, while we would hesitate to claim that in cases in which no ductus can be seen its existence is excluded, we would emphasize that when a patent ductus is visualized it is unmistakeable.

In Case 4, the posterior approach was used and, although a structure was seen originating from the anterior aspect of the aortic arch, the limited field of vision made it impossible to be certain that we were not looking at the pulmonary artery itself. In the light of our later experiences with Cases 5 and 6 we now feel convinced that this was a patent ductus.

In childhood before the typical machinery murmur of patent ductus has developed, there seems to be 
some value in thoracoscopy to differentiate it from other conditions, especially auricular septal defect. This difficulty was noted by Taussig (1947) who stated " in infancy there is nothing in this age group to differentiate this murmur from the systolic murmur associated with the patent ductus arteriosus or one caused by ventricular septal defect." There appears to be a place for thoracoscopy here. If the ductus is short it is more difficult to see than if it is long, and a "keyhole" ductus is almost certainly invisible.

The arch of the aorta can be viewed clearly and in coarctation the constriction can be seen and its extent estimated; one can also make sure that the calibre of the vessel distal to the coarctation is such that it can be anastomosed to the proximal segment. These items of information are difficult and usually impossible to obtain by X-ray methods and angiography. Crafoord (1945) reported two cases that were found inoperable at thoracotomy, and others have undoubtedly occurred.

Blalock (1946 and 1948) stipulates that a low pressure must be found in the pulmonary arteries before his operation is indicated. In doubtful cases in which a catheter cannot be passed through the pulmonary valve a thoracotomy is necessary to obtain this reading. As is demonstrated in Case 7 it may be possible to insert a needle into the pulmonary artery under view through the thoracoscope and thus obtain the pressure reading. This may not always be possible owing to anatomical varia- tions but we claim that if thoracoscopy is practised as a routine investigation in these cases some thoracotomies may be obviated.

It is not always easy to diagnose the condition of double aortic arch or to differentiate the various types of anomaly involved. Sweet et al. (1947) describe a case in which the aortic arch was thought to be right sided, with a left-sided arch compressing the trachea; a left thoracotomy showed that the major arch was in fact left sided, but passed behind the œsophagus into the right thoracic cavity, where it was joined by a small right arch which produced the compression. A subsequent right thoracotomy enabled them to divide the right arch and effect a cure. Preliminary thoracoscopy in this type of case would enable a more accurate diagnosis to be made before operation, though here the procedure would have to be bilateral.

\section{CONCLUSIONS}

The technique of thoracoscopy as an aid to diagnosing certain congenital cardiac conditions has been discussed.

Seven cases are described in which this procedure was employed. The scope and limitations of this method have been briefly discussed.

We wish to thank Professor G. A. Elliott, Witwatersrand University, for permission to publish Case 7, and Dr. S. Selby, Coronation Hospital, for Case 2.

We are indebted to Dr. J. L. Lovibond for much helpful criticism, and to Miss D. M. Barber for the drawings.

\section{REFERENCES}

Blalock, A., and Taussig, H. B. (1945). J. Amer. med. Ass., 128, 189.

- - (1946). Bull. N.Y. Acad. Med., 20, 2, 57.

- (1946). Ann. Surg., 124, 879.

- , and Bahnson, H. T. (1948). Annals Roy. Cuil. Surgeons of England, 3, 2, 57.

Crafoord, C., and Nylin, J. (1945). J. Thorac. Surg., 14, 347 .
Sweet, R. H., Findlay, C. W., and Reyersbach, G. C. (1947). J. Paed., 30, 1.

Taussig, H. B. (1947). Congenital Malformations of the Heart. Oxford Univ. Press.

Williams, E. R. (1940). Brit. J. Radiol., 18, 323. 